\title{
Metastatic Gastric cancer: Real world scenario from a developing country
}

\author{
Sandip Ganguly, Bivas Biswas, Joydeep Ghosh, Deepak Dabkara
}

\begin{abstract}
Aim: Data on epidemiology and outcome in metastatic stomach carcinoma patients from India are scarce. We aimed to evaluate clinical features and treatment outcome in patients treated at our center. Materials and Methods: This is a single institutional review of metastatic gastric carcinoma patients treated between May 20II and October 2016. Patients who received at least one cycle of chemotherapy were included for modified intent-to-treat survival analysis. Results: A total of I43 patients were diagnosed with metastatic stomach carcinoma with a median age of 56 years (range: 29-86). The most common symptoms were abdominal pain in $112(78 \%)$ patients. The most common site was body in 81 (57\%) patients. Common site of metastasis was peritoneum in $86(60 \%)$ and liver in (62\%). Seventy-one (50\%) patients were eligible for survival analysis. Common chemotherapy regimens were capecitabine-cisplatin in $27(38 \%)$ and EOX in 22 (31\%) patients. Survival status could not be assessed in 29 (4I\%) patients who lost to follow-up. After a median follow-up 9.7 months (range: $0.5-37.7$ ), median progression-free survival (PFS) was 7.9 months (range: $0.5-23.9$ ) and median overall survival (OS) was 12.2 months (range: 0.5-37.7). The Eastern Cooperative Oncology Group (ECOG) performance status (PS) $\geq 2$ and the presence of linitis plastica showed a trend toward inferior PFS ( $P=0.052$ and 0.053 , respectively) only in univariate analysis. Female sex and ECOG PS $\geq 2$ predicted inferior OS in both univariate and multivariate analysis $(P=0.012,0.02$ and 0.03 and 0.05 , respectively). Conclusions: Platinum-based doublet chemotherapy was used in the majority of patients. The overall outcome was comparable to that of the available literature. Female sex and ECOG PS $\geq 2$ predicted the inferior outcome.

Key words: Chemotherapy, gastric cancer, metastases
\end{abstract}

\section{Introduction}

Gastric cancer has wide geographical variation being more common in the eastern part of Asia. ${ }^{[1]}$ Compared to the global data of 952,000 cases/year, the incidence of gastric cancer in India is very low with an annual number of new cases being approximately only 63,000 with slight male predominance over a female with the ratio being $2: 1 .^{[2]}$

Treatment of early gastric cancer consists of surgery followed by either perioperative chemotherapy or adjuvant chemotherapy with or without radiotherapy. ${ }^{[3]}$ In metastatic disease, systemic chemotherapy forms the main backbone of treatment with platinum, 5-Fluorouracil analog agents along with either anthracyclines or taxanes. With these agents, the prognosis is still dismal with maximum median overall survival (OS) of around 11 months. ${ }^{[4-6]}$ Trastuzumab has shown an improved response in Her2 positive disease compared to standard systemic chemotherapy with median OS of 13.8 months. ${ }^{[7]}$ Immune checkpoint inhibitors (anti-progressive disease [PD] 1/PDL1 antibodies) are showing promising activities in gastric cancer. ${ }^{[8]}$ Majority of gastric cancer presents in advanced stages leading to a dismal prognosis. From India, 5 years survival of patients with all stomach cancer has been reported to be around $18.7 \% .{ }^{[9]}$ Compared to other countries, limited literatures are available from India regarding the epidemiology, treatment, and outcome of patients with metastatic gastric cancer (MGC). Here, we have described the clinicopathological features and outcomes of patients with a diagnosis of MGC.

\section{Materials and Methods}

\section{Patients}

This is a single institutional data review of patients with MGC registered and treated in the Department of Medical Oncology of Tata Medical Center, Kolkata from May 2011 to October 2016. Patients who were initially treated with curative intent and then developed recurrent metastatic disease were also

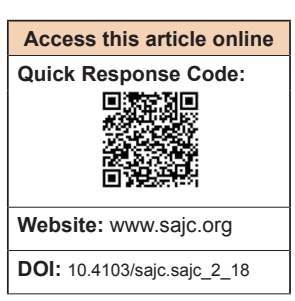

Department of Medical Oncology, Tata Medical Center, Kolkata, West Bengal, India

Correspondence to: Dr. Sandip Ganguly, E-mail: dr. babumashai@gmail.com included in the analysis. Patients who received at least one cycle of chemotherapy were included for survival analysis in an intent-to-treat analysis. Clinico-epidemiological features and treatment details were analyzed for all patients. Ethical clearance was taken from the Institute Review Board.

\section{Diagnosis and work-up}

All patients underwent tissue diagnosis either from upper gastrointestinal endoscopic biopsy or from other accessible metastatic site. In the case of latter, an upper gastrointestinal endoscopy was required for confirmation of primary. Metastatic work-up was done with computed tomography of thorax and abdomen. ${ }^{99}$ technetium bone scintigraphy was performed in the case of symptomatic bone pain or high alkaline phosphatase in the absence of liver metastasis. Her2 testing was performed by immunohistochemistry or fluorescent in situ hybridization in selected cases of tumor in gastroesophagial junction or proximal stomach in patients who could have afforded for trastuzumab

\section{Treatment and response evaluation}

All patients underwent palliative chemotherapy after confirmation of diagnosis and metastatic work-up, if the Eastern Cooperative Oncology Group (ECOG) performance status was between 0 and 2 and organ functions were within normal limits. EOX ((intravenous epirubicin $50 \mathrm{mg} / \mathrm{m}^{2}$ on day 1 , oxaliplatin $130 \mathrm{mg} / \mathrm{m}^{2}$ on day 1 , and capecitabine $1,250 \mathrm{mg} / \mathrm{m}^{2}$ daily D1-21, cycle repeated every 21 days) (ref) or Cape-Cis (capecitabine $1,700 \mathrm{mg} / \mathrm{m} 2$ daily D1-14, cisplatin $75 \mathrm{mg} / \mathrm{m}^{2}$ on day 1 , cycle repeated for every 21 days) or Cape-OX ([capecitabine $1700 \mathrm{mg} / \mathrm{m}^{2}$ daily D1-14, oxaliplatin $130 \mathrm{mg} / \mathrm{m}^{2}$ on day 1 , and cycle repeated every 21 days]) were used as preferred the first-line treatment. Trastuzumab was added for Her $23+$ on IHC or FISH amplified along with platinum and capecitabine. Other chemotherapeutic regimes which were used are docetaxel $\left(75 \mathrm{mg} / \mathrm{m}^{2}\right.$ every 21 days), irinotecan $(300 \mathrm{mg} / \mathrm{mt} 2 \mathrm{D} 1$ every 21 days), paclitaxel

This is an open access journal, and articles are distributed under the terms of the Creative Commons Attribution-NonCommercial-ShareAlike 4.0 License, which allows others to remix, tweak, and build upon the work non-commercially, as long as appropriate credit is given and the new creations are licensed under the identical terms.

For reprints contact: reprints@medknow.com 
( $80 \mathrm{mg} / \mathrm{mt} 2$ weekly) in those with recurrent disease. Toxicities were graded as per the common Terminology Criteria for adverse events version $4{ }^{[10]}$ Patients were assessed every 3-4 cycles for response assessment. Complete remission (CR), partial response (PR), stable disease (SD), and PD were defined according to the response evaluation criteria in solid tumors v1.1) criteria. ${ }^{[11]}$ Overall response rate (ORR) was defined as the sum of CR + PR. Clinical benefit rate (CBR) was defined as the sum of $\mathrm{CR}+\mathrm{PR}+\mathrm{SD}$.

\section{Statistical analysis}

Descriptive statistics were used for demographic and clinical characteristics. A Chi-square or Fisher's exact test was used to detect associations between qualitative variables. The Student's $t$-test or Wilcoxon rank-sum test was applied to compare between categorical and continuous variables. Survival was estimated with the Kaplan-Meier method, and survival estimates were compared using the log-rank test. Data were censored on January 31, 2017. Patients who were lost to follow-up were censored at the date of last contact/follow-up. Patients who were alive on January 31, 2017 were censored for overall survival analysis. The Cox proportional hazard model was used in the univariate analysis to detect outcome differences between groups. Stepwise multivariate Cox regression analysis was performed to identify the predictors of outcome. Factors with significance $(P<0.1)$ in the univariate analysis were entered into multivariate analysis. Progression-free survival (PFS) was calculated from the date of diagnosis of metastatic disease to the date of clinical or radiological disease progression. Overall survival (OS) was calculated from the date of diagnosis of metastatic disease to the date of death from any cause. Patients who were lost to follow-up or who had abandoned treatment was also included in the event-free survival and overall survival analyses, and the outcomes for these patients were confirmed by telephone contact. Patients who received at least one cycle of chemotherapy were included for a modified intent to treat survival analysis. Treatment abandonment was included in the survival analysis in the present study as it has been proposed that patients who do not comply with or who abandon treatment be included in survival analysis for studies from developing nations to provide a true picture of outcomes from these countries. STATA/SE 11.0 (StataCorp, College Station, Texas, USA) was used for statistical analysis. ${ }^{[12]}$

\section{Results}

\section{Clinico-pathological features}

Our department in the past 5 years has seen 279 patients with gastric cancer. Out of that $118(82.5 \%)$ patients presented with de novo metastatic disease. Twenty-five (17.5\%) patients developed recurrent metastatic disease after initial treatment. Median age of the study population was 56 years (range 29-86) with a male predominance (M: F:92:51). Median body mass index (BMI) was $19.65 \mathrm{~kg} / \mathrm{mt} 2$ (14.3-28.8). Baseline characteristics of the patients are shown in Table 1 .

Most common presenting symptom among the patient was pain abdomen which was seen in $63.6 \%$ of patients. Other common symptoms were weight loss, dyspepsia, vomiting among others as shown in Table 1. Gastric outlet obstruction was seen in $33(23.6 \%)$ of patients. Endoscopy features showed linitis plastic in $9(6.2 \%)$ patients.
The peritoneum was the most common site of metastatic disease in our study and $12(8 \%)$ patients had bone metastases. More than one site of metastatic disease was present in $104(75 \%)$ of our patients.

\section{Treatment, toxicities, and response}

Out of 143 patients only 71 patients took at least one cycle of chemotherapy as shown in Figure 1. They were included in the modified intent to treat survival analysis. Common chemotherapeutics regime which was used were Cape-Cis (38\%) followed by EOX (30.9\%) followed by CAPOX (7\%), docetaxel-based regime (9.8) and others (14\%). Only 2 patients received trastuzumab-based chemotherapy in the upfront setting. Twenty-one patients only received further chemotherapy on systemic progression

Table 1: Baseline characteristics of the patient

\begin{tabular}{lc} 
Characteristics & $n(\%)$ \\
\hline ECOG performance score & $2(1.3)$ \\
0 & $60(41.9)$ \\
1 & $47(32.6)$ \\
2 & $29(20.2)$ \\
3 & $5(3.4)$ \\
4 & \\
Site, $n$ (\%) & $44(30)$ \\
Proximal & $81(57)$ \\
Body & $18(13)$ \\
Distal & $33(26)$ \\
Gastric outlet obstruction & $9(6.2)$ \\
Linitis plastica & \\
Symptoms (\%) & 63.6 \\
Pain abdomen & 41.2 \\
Weight loss & 32.8 \\
Dyspepsia & 20.9 \\
Vomiting & 12.5 \\
Malena & 5.6 \\
Hemetemesis & \\
Site (\%) & 50.3 \\
Lymph nodes & 60.3 \\
Peritoneum & 43 \\
Liver & 15 \\
Lung and pleura & 9.9 \\
Ovary & 7.6 \\
Bones & 3.4 \\
Others &
\end{tabular}

ECOG=Eastern coopeative oncology group

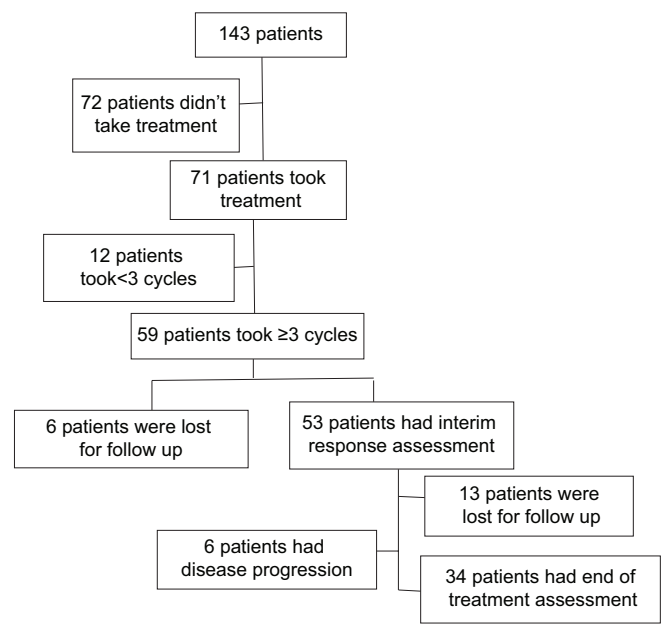

Figure 1: Consort Diagram of the Study Population

South Asian Journal of Cancer Volume 7 Issue 3 •uly-September 2018 
with single-agent docetaxel $(71.4 \%)$ being the most common regime.

Interim response assessment was assessed on $53(75 \%)$ patients-PR in 19 (26.7\%), SD in 28 (39.4\%), PD in $6(8.4 \%)$ patients with an ORR of $26.7 \%$, and CBR of $66.1 \%$. End of treatment response assessment was done in $34(48 \%)$ patients-CR in $3(4.2 \%)$, PR in 4 (5.6\%), SD in $23(32.3 \%)$, and PD in $4(5.6 \%)$ patients. ORR was seen in $20.5 \%$ of patients and CBR was seen in $88 \%$ of patients. Thirteen patients $(18.3 \%)$ developed PD in the new site at the time of progression.

After a median follow-up of 9.7 months (0.5-37.7), median PFS was 7.9 months $(0.5-23.9)$ and median OS was 12.2 months (0.5-37.7) as shown in Figures 2 and 3, respectively.

ECOG performance status (PS) $\geq 2$ and the presence of linitis plastica showed a trend toward inferior PFS $(P=0.052$ and 0.053 , respectively) only in univariate analysis. Female sex and ECOG PS $\geq 2$ predicted inferior OS in both univariate and multivariate analysis $(P=0.012,0.02$ and 0.03 and 0.05 , respectively) as shown in Table 2 .

Toxicity profile of the patients is shown in Table 3 . The most common Grade 3-4 toxicities were diarrhea in $8(11 \%)$, mucositis in $6(8.4 \%)$, and neutropenia in $5(7 \%)$ patients.

\section{Discussion}

Gastric cancer has wide geographical variation while being more common in Eastern Asia, East Europe and being less in North America, India, rest of Europe. ${ }^{[1]}$ Within India, there is a geographical variation with a maximum incidence of gastric cancer being in the southern and north eastern part of India. ${ }^{[13]}$ There is limited literature from India with the outcome of patients with stomach cancer with no available literature regarding metastatic settings.

The median age of our study population was 56 years which is less compared to the rest of the world ${ }^{[14]}$ but comparable to the available literature from India ${ }^{[15]}$ Most common symptoms were pain abdomen $(63.6 \%)$ and weight loss $(41.2 \%)$ which was similar to the study done by Barad et al. ${ }^{[16]}$

Peritoneum (60.3\%) and distant lymph nodes (50.3\%) were the most common sites of metastases in our study as compared to the study by Riihimäki et al. where liver (38\%) and peritoneum were the most common sites. ${ }^{[17]}$ In our study, $8 \%$ of patients had bone metastases. Incidence of bone metastases varies from $0.9 \%$ to $13 \%{ }^{[18,19]}$

In our study, PS and female sex were the poor prognostic factors. PS 2 or more is a well-proven risk factor in many studies. ${ }^{[20]}$ Regarding sex of the patient and prognosis, our study results were comparable to those done by Lee et al. ${ }^{[20]}$

There is no single standard chemotherapeutic regime in treating patients with MGC and it varies region wise. Our patients received an assortment of chemotherapeutic regimes which have proven benefits in the available literature. None of our patients received combination chemotherapy with docetaxel. The rationale for the same was made to prevent excess toxicities in the patients as their baseline median BMI was only within normal range. In our study, the ORR is less than what has been reported in the literature. Reason for the same

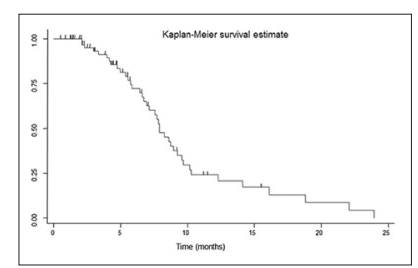

Figure 2: Kaplan-Meir graph showing progression free survival of the treatment group

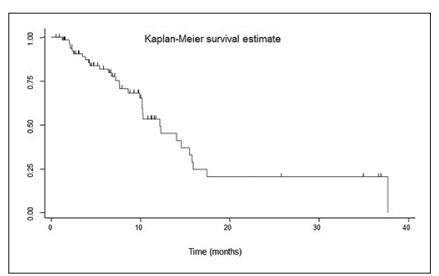

Figure 3: Kaplan-Meir graph showing overall survival of the treatment group

Table 2: Univariate and multivariate analysis for progression-free survival and overall survival

\begin{tabular}{|c|c|c|c|c|c|c|c|c|c|}
\hline \multirow[t]{2}{*}{ Variables } & \multirow[t]{2}{*}{ Category } & \multicolumn{3}{|c|}{ PFS (univariate) } & \multicolumn{3}{|c|}{ OS (univariate) } & \multicolumn{2}{|c|}{ OS (multivariate) } \\
\hline & & HR & CI & $P$ & HR & CI & $P$ & HHR & $P$ \\
\hline \multirow[t]{2}{*}{ Age (years) } & $\leq 52(n=35)$ & 1 & & 0.23 & & & & & \\
\hline & $>52(n=36)$ & 0.67 & $0.35-1.29$ & & & & & & \\
\hline \multirow[t]{2}{*}{ Sex } & Male $(n=26)$ & 1 & & 0.45 & & & & 1.1 & 0.03 \\
\hline & Female $(n=45)$ & 0.76 & $0.38-1.53$ & & & & & 0.41 & \\
\hline \multirow[t]{2}{*}{ BMI } & $\leq 18(n=21)$ & 1 & & 0.32 & & & & & \\
\hline & $>18(n=50)$ & 0.68 & $0.31-1.147$ & & & & & & \\
\hline \multirow[t]{2}{*}{ ECOG PS } & 0 and $1(n=41)$ & 1 & & 0.052 & & & & 1 & 0.05 \\
\hline & 2 and $3(n=30)$ & 1.96 & $0.99-3.87$ & & & & & 2.14 & \\
\hline \multirow[t]{2}{*}{ Duration of symptoms (months) } & $\leq 3(n=55)$ & 1 & & 0.12 & & & & & \\
\hline & $>3(n=16)$ & 1.89 & $0.85-4.23$ & & & & & & \\
\hline \multirow[t]{2}{*}{ Weight loss } & No $(n=30)$ & 1 & & 0.86 & & & & & \\
\hline & Yes $(n=41)$ & 1.06 & $0.56-2.02$ & & & & & & \\
\hline \multirow[t]{2}{*}{ Gastric outlet obstruction } & No $(n=59)$ & 1 & & 0.78 & & & & & \\
\hline & Yes $(n=12)$ & 0.85 & $0.26-2.68$ & & & & & & \\
\hline \multirow[t]{3}{*}{ Site of primary } & Proximal $(n=22)$ & 1 & & & & & & & \\
\hline & Body $(n=40)$ & 1.03 & $0.53-2.01$ & 0.92 & & & & & \\
\hline & Distal $(n=9)$ & 0.41 & $0.5-3.16$ & 0.39 & & & & & \\
\hline \multirow[t]{2}{*}{ Linitis plastica } & No $(n=66)$ & 1 & & 0.53 & & & & & \\
\hline & Yes $(n=5)$ & 2.85 & $0.99-8.23$ & & & & & & \\
\hline \multirow[t]{2}{*}{ Number of metastatic site } & Single $(n=16)$ & 1 & & 0.2 & & & & & \\
\hline & $\geq 2(n=55)$ & 1.73 & $0.74-4.04$ & & & & & & \\
\hline
\end{tabular}

ECOG=Eastern coopeative oncology group, PS=Performance status, BMI=Body mass index, PFS=Progression-free survival, CI=Confidence interval, OS=Overall survival, $\mathrm{HR}=$ Hazard ratio, HHR=High heart rate 
Table 3: Toxicity profile of the patients

\begin{tabular}{lcccc}
\hline Toxicity & $\begin{array}{c}\text { Grade } \mathbf{1} \\
(\%)\end{array}$ & $\begin{array}{c}\text { Grade } 2 \\
(\%)\end{array}$ & $\begin{array}{c}\text { Grade } 3 \\
(\%)\end{array}$ & $\begin{array}{c}\text { Grade 4 } \\
(\%)\end{array}$ \\
\hline Vomiting & $4(5.6)$ & $11(15.4)$ & $2(2.8)$ & $1(1.4)$ \\
Diarrhoea & $7(9.8)$ & $8(11.2)$ & $4(5.6)$ & $4(5.6)$ \\
Neutropenia & $1(1.4)$ & $11(15.4)$ & $4(5.6)$ & $1(1.4)$ \\
Hand foot syndrome & $3(4.2)$ & $2(2.8)$ & $1(1.4)$ & $1(1.4)$ \\
Neuropathy & $2(2.8)$ & & & \\
Mucositis & $3(4.2)$ & $1(1.4)$ & $5(7)$ & $1(1.4)$ \\
\hline
\end{tabular}

may be attributed to nonusage of docetaxel-based regime, dose modification of capecitabine in view of toxicity, inherent biology of the disease. However, CBR in our study was more than what was reported by Sirohi et al. ${ }^{[15]}$ The marked increase of median PFS and median OS maybe a falsely high value due to higher drop out of patients in the study period leading to censoring of data.

The study has some inherent limitations. This was a retrospective study. Many patients were not assessed either at the interim or at the end of treatment due to poor compliance. Poor compliance can be either due to logistic issues, financial burdens, deterioration of performance status of the patient, toxicities, early, and rapid disease progression, etc., Due to the poor compliance survival status of many patients was not available.

However, our study does have some strength. This is one of the few published clinical data regarding patients with metastatic stomach cancer from resource poor setting like India. All the patients were treated with standard chemotherapeutic regimes. Only those patients were included for survival analysis who received at least one cycle of chemotherapy in an intent to treat survival analysis thus attempting to reduce censoring as much as possible. It has considered the issue of compliance which is a serious issue in a developing country like India. We also made a sincere effort to describe the toxicity pattern of patients with chemotherapeutic agents in a real-world setting. This is a single institutional data where data is recorded electronically, thus leading to no data loss.

\section{Conclusion}

Our study has made a veritable attempt to determine the clinical profile and outcome of patients in India with MGC including compliance to treatment. Further prospective multicentric studies are required to determine the proper survival of Indian patients treated with the standard chemotherapeutic regime.

Financial support and sponsorship

Nil.

\section{Conflicts of interest}

There are no conflicts of interest.

\section{References}

1. Alberts SR, Cervantes A, van de Velde CJ. Gastric cancer: Epidemiology, pathology and treatment. Ann Oncol 2003;14 Suppl 2:ii31-6.

2. Ferlay J, Soerjomataram I, Ervik M, Dikshit R, Eser S, Mathers C, et al. GLOBOCAN 2012 v1.0, Cancer Incidence and Mortality Worldwide: IARC CancerBase No. 11 [Internet]. Lyon, France: International Agency for Research on Cancer; 2013.

3. Elimova E,Shiozaki H,Wadhwa R,Sudo K,Chen Q, Estrella SJ, et al. Medical management of gastric cancer:A 2014 update. World J Gastroenterol. 2014;20: 13637-47.

4. Kang YK, Kang WK, Shin DB, Chen J, Xiong J, Wang J, et al. Capecitabine/cisplatin versus 5-fluorouracil/cisplatin as first-line therapy in patients with advanced gastric cancer: A randomised phase III noninferiority trial. Ann Oncol 2009;20:666-73.

5. Cunningham D, Starling N, Rao S, Iveson T, Nicolson M, Coxon F, et al. Capecitabine and oxaliplatin for advanced esophagogastric cancer. N Engl J Med 2008;358:36-46.

6. Chen XL, Chen XZ, Yang C, Liao YB, Li H, Wang L, et al. Docetaxel, cisplatin and fluorouracil (DCF) regimen compared with non-taxane-containing palliative chemotherapy for gastric carcinoma: A systematic review and meta-analysis. PLoS One 2013;8:e60320.

7. Bang YJ, Van Cutsem E, Feyereislova A, Chung HC, Shen L, Sawaki A, et al. Trastuzumab in combination with chemotherapy versus chemotherapy alone for treatment of HER2-positive advanced gastric or gastro-oesophageal junction cancer (ToGA): A phase 3, open-label, randomised controlled trial. Lancet 2010;376:687-97.

8. Tran PN, Sarkissian S, Chao J, Klempner SJ. PD-1 and PD-L1 as emerging therapeutic targets in gastric cancer: Current evidence. Gastrointest Cancer 2017;7:1-1.

9. Allemani C, Weir HK, Carreira H, Harewood R, Spika D, Wang XS, et al. Global surveillance of cancer survival 1995-2009: Analysis of individual data for 25,676,887 patients from 279 population-based registries in 67 countries (CONCORD-2). Lancet 2015;385:977-1010.

10. CTCAE4.0. Available from: https://www.ctep.cancer.gov/ protocoldevelopment/electronic_applications/ctc.htm. [Last accessed on 2017 Dec 12].

11. Eisenhauer EA, Therasse P, Bogaerts J, Schwartz LH, Sargent D, Ford R, et al. New response evaluation criteria in solid tumours: Revised RECIST guideline (version 1.1). Eur J Cancer 2009;45:228-47.

12. StataCorp. Stata Statistical Software: Release 11. College Station, TX: StataCorp LP; 2009.

13. Sharma A, Radhakrishnan V. Gastric cancer in India. Indian J Med Paediatr Oncol 2011;32:12-6.

14. Yang D, Hendifar A, Lenz C, Togawa K, Lenz F, Lurje G, et al. Survival of metastatic gastric cancer: Significance of age, sex and race/ethnicity. J Gastrointest Oncol 2011;2:77-84.

15. Sirohi B, Rastogi S, Dawood S, Talole S, Ramadwar M, Shetty N, et al. Treatment of patients with advanced gastric cancer: Experience from an Indian tertiary cancer center. Med Oncol 2014;31:138.

16. Barad AK, Mandal SK, Harsha HS, Sharma BM, Singh TS. Gastric cancer-a clinicopathological study in a tertiary care centre of North-Eastern India. J Gastrointest Oncol 2014;5: 142-7.

17. Riihimäki M, Hemminki A, Sundquist K, Sundquist J, Hemminki K. Metastatic spread in patients with gastric cancer. Oncotarget 2016;7:52307-16.

18. Ahn JB, Ha TK, Kwon SJ. Bone metastasis in gastric cancer patients. J Gastric Cancer 2011;11:38-45.

19. Turkoz FP, Solak M, Kilickap S, Ulas A, Esbah O, Oksuzoglu B, et al. Bone metastasis from gastric cancer: The incidence, clinicopathological features, and influence on survival. J Gastric Cancer 2014; 14:164-72.

20. Lee J, Lim T, Uhm JE, Park KW, Park SH, Lee SC, et al. Prognostic model to predict survival following first-line chemotherapy in patients with metastatic gastric adenocarcinoma. Ann Oncol 2007;18:886-91.

\section{$4^{\text {th }}$ AMMO Conference \\ 11-12 August 2018, Nashik \\ Dr Shailesh Bondarde - shaileshbondarde@yahoo.com Www.medintelservices.com \\ Conference Organizer : Kashish Parikh +91-98190-25850 and kashishparikh@gmail.com}

